\title{
On-demand patterning for organic light-emitting diodes using laser irradiation
}

\author{
Ryota Sugimoto, ${ }^{1}$ Masahiro Morimoto, ${ }^{* 2}$ and Shigeki Naka ${ }^{2}$ \\ ${ }^{1}$ Graduate School of Science and Engineering, University of Toyama,3190 Gofuku, Toyama, 930-8555, Japan \\ ${ }^{2}$ Academic Assembly Faculty of Engineering, University of Toyama,3190 Gofuku, Toyama, 930-8555, Japan
}

E-mail: morimoto@eng.u-toyama.ac.jp

We investigated the patterning of organic light-emitting diodes using a blue laser irradiation after making uniform device. Laser patterning was carried out in the atmosphere after the organic layer was deposited. The laser irradiation part was quenched, and it was shown that optional patterning was possible. This technique is expected as a fabrication technique for on-demand pattern emission.

8 Keywords: organic light-emitting diodes, laser 9 patterning, on-demand patterning

Organic light-emitting diodes (OLEDs) have 11 attracted much interest, such as self-emission, high brightness, 12 high contrast, and so on. ${ }^{3-5}$ They have practically used in 13 various applications such as lighting and a display for 14 smartphones and televisions. For various device applications, 15 a variety of simple patterning techniques are required. 16 However, this is difficult with conventional mask patterning.

17 This is because the cost of mask preparation could be large

18 for various requirements, deterioration of the mask, and the

19 like. Free patterning is required without photomasks or

20 shadow masks. Inkjet printing method is being studied as one

21 of the manufacturing methods to satisfy this requirement.
Inkjet printing patterning methods such as dye doping, ${ }^{6}$ charge injection layer patterning, ${ }^{7}$ and self-alignment ${ }^{8-12}$ are being studied. The inkjet printing method has problems in the process of ink adjustment and drying. It has been studied as a patterning technology using light such as photobleaching, ${ }^{13,14}$ photo-reaction ${ }^{15,16}$ and color tuning ${ }^{17,18}$.

In this research, we have studied of patterned emission in OLEDs using photo-reaction of the organic semiconductors without the conventional mask. The patterned OLEDs were evaluated the characteristics of emission.

5,6,11,12-tetraphenyltetracene (rubrene) was used as an emission material. Rubrene is known to form endoperoxide by photo irradiation (Fig. S1) ${ }^{19-23}$ It has also been reported that rubrene functions as a light-emitting layer even in an extremely thin film. ${ }^{24-27}$ Indium-tin-oxide (ITO) coated glass substrates were cleaned using ultrasonication and UV-ozone treatment. N,N'-di-1-naphthyl-N,N'-diphenylbenzidine ( $\alpha$ NPD) was used as a hole transport layer $(70 \mathrm{~nm})$, rubrene (1 $\mathrm{nm}$ ) and bis(8-hydroxy-2-methylquinoline)-(4phenylphenoxy) aluminum (BAlq) was used as an electron transport layer $(30 \mathrm{~nm})$ (Fig. S2). All layers were formed on the ITO substrate by vacuum evaporation. Subsequently, a blue laser (wavelength of $445 \mathrm{~nm}$ ) was irradiated from the organic layer side in the atmosphere. The photo-patterning was performed using a FABOOL Laser Mini (SmartDIYs), which was $\mathrm{x}-\mathrm{y}$ scannable and could be adjusted for the output power by pulse width modulation. The maximum output

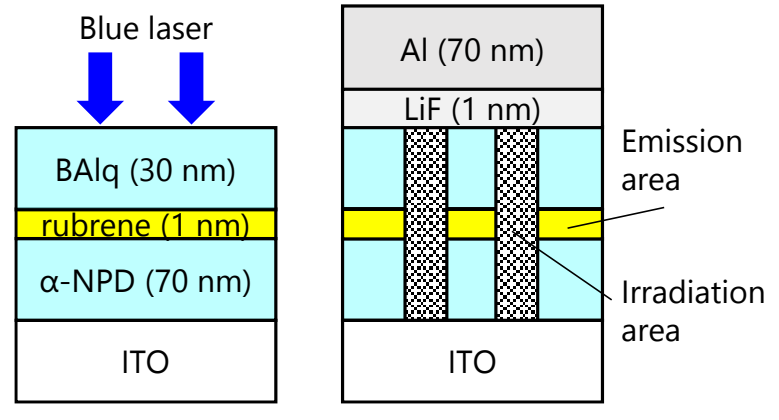

Figure 1. Fabrication process and device structure.

50 power of the laser was $1.6 \mathrm{~W}$. In this study, it was used with 51 maximum power continuous light to avoid discontinuous 52 laser irradiation. After patterning, $\mathrm{LiF}(1 \mathrm{~nm}) / \mathrm{Al}(70 \mathrm{~nm})$ 53 stack was formed as cathodes in vacuum. The device area was $542 \times 2 \mathrm{~mm}^{2}$. Figure 1 shows the fabrication and patterning 55 processes. Current density and luminance versus applied 56 voltage characteristics of devices were measured using a 57 semiconductor parameter analyzer (B1500A, Keysight 58 Technologies) and a luminance meter (BM-9, Topcon). The 59 emission spectra were measured using an optical fiber 60 spectrometer (Avaspec-UV/Vis/NIR, Avantes). Absorption 61 spectra of the thin films were measured using an UV/VIS 62 optical spectrometer (UV-1650PC, Shimadzu).

63 Figure 2 shows the absorption spectra of the materials 64 used. The absorption coefficients of rubrene, $\alpha$-NPD and 65 BAlq at $445 \mathrm{~nm}$ were 18,800, 2,600 and $1,900 \mathrm{~cm}^{-1}$, 66 respectively. Absorption coefficient at the laser wavelength 67 of $445 \mathrm{~nm}$ is extremely high for rubrene, and the photo68 reaction by laser irradiation can be expected. Figure 3 shows 69 an example of the decrease in PL intensity of the rubrene after

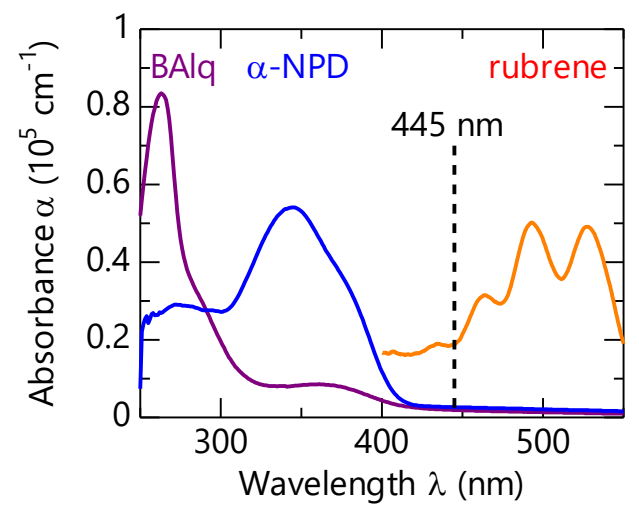

Figure 2. Absorption coefficient of rubrene, $\alpha-\mathrm{NPD}$, and BAlq thin films. The dash line is the wavelength of the blue laser at $445 \mathrm{~nm}$. 


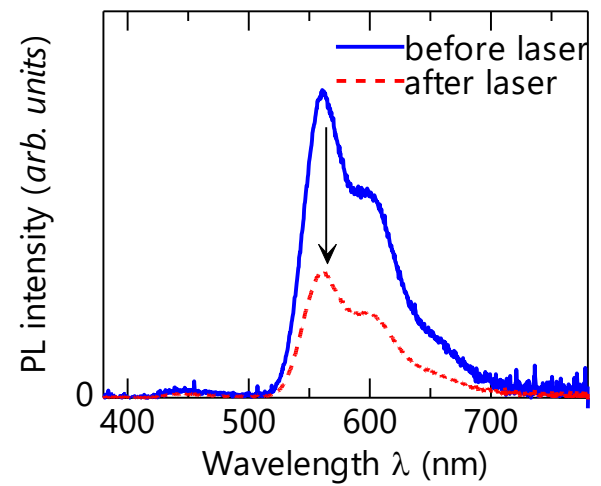

Figure 3. Photoluminescent spectra of rubrene thin films before and after laser irradiation.

1 laser irradiation. It is indicated that the light degradation of

2 the rubrene could be generated by the laser beam irradiation 3 in the atmosphere.

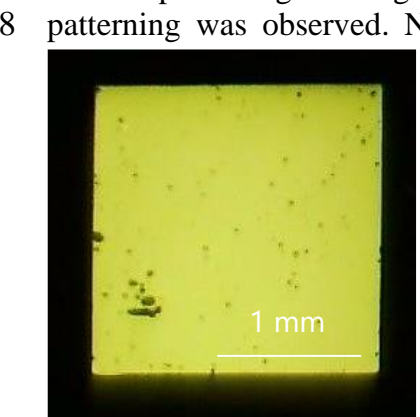

(a) pristine

(c) $5,000 \mathrm{~mm} / \mathrm{min}$

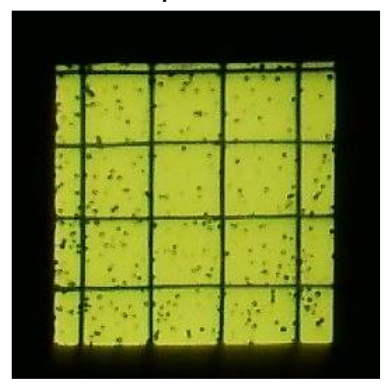

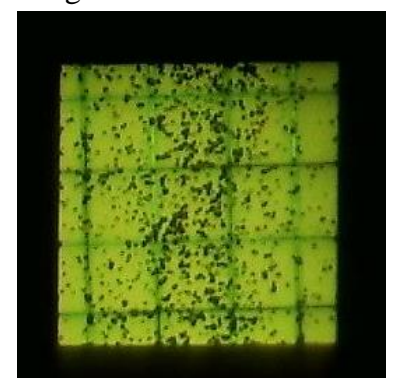

(b) $8,000 \mathrm{~mm} / \mathrm{min}$

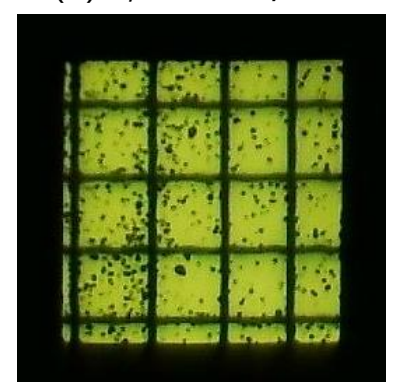

(d) $1,000 \mathrm{~mm} / \mathrm{min}$
Figure 4. Emission images of (a) pristine device and laser patterned devices with scanning speed of (b) 8,000, (c) 5,000, and (d) 1,000 $\mathrm{mm} / \mathrm{min}$.

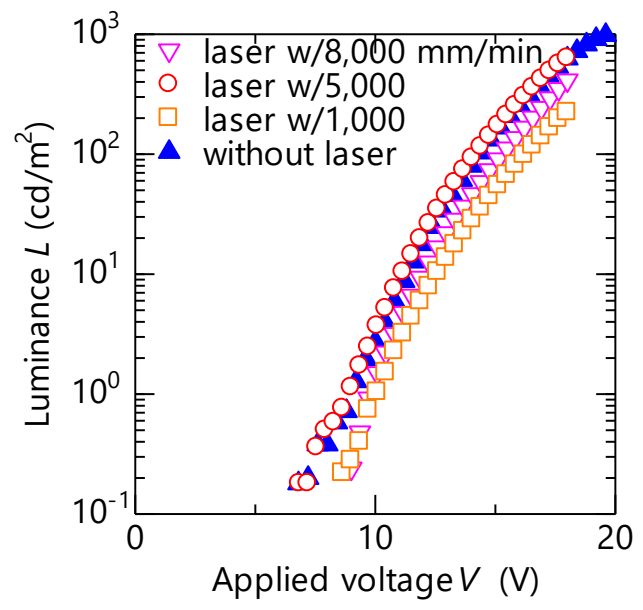

Figure 5. Luminance versus applied voltage characteristics of the devices with and without patterning at scanning speed of 1,000, 5,000, and $8,000 \mathrm{~mm} / \mathrm{min}$.

19 irradiation was observed. This indicates that laser ablation

20 does not occur, a photo-reaction occurs, and the altered

21 material remains in place. If ablation occurs, the organic layer

22 of the laser irradiation area disappears and a short occurs

23 between the electrodes. The luminance values decreased with

24 slow scanning speed because the luminance measurement 25 area $(\phi 1.5-2.0 \mathrm{~mm})$ was almost the same as the device area, 26 namely, the clear pattern led to decrease the emitting area.
Photo-oxidation mainly occurred in rubrene layer by light irradiation, and no light emission occurs in the lightirradiated area. However, the PL spectrum of the device changed by the laser irradiation and the spectral changes were from not only rubrene but also $\alpha$-NPD (Fig. S5). In contrast, the pattern emission was also obtained in a device consisting of $\alpha$-NPD/BAlq containing no rubrene since $\alpha$-NPD has been known as the emitting material (Figs. S6 and S7). ${ }^{28} \alpha-N P D$ might also have the reduction of the carrier transport ${ }^{29}$ and the photo-degradation ${ }^{30}$ due to light irradiation. The decline of carrier transport properties led to a reduction in carrier recombination efficiency in the emitting layer, resulting in no light emission.

Pattern emission of OLED by laser irradiation was investigated. Though the degradation of the device characteristics was confirmed depending on the irradiation quantity of the laser, the characteristics equivalent to no laser irradiation were obtained under the condition of the appropriate laser irradiation quantity. This pattern was probably due to the photo-degradation and the reduction of the carrier transport. However, no significant degradation of the device was observed and the patterning process in this work may be expected to apply under a little oxygen, i.e., in a vacuum chamber or glove box. This method can be used as a wide range of on-demand patterning methods.

This work was supported by Kenjiro Takayanagi Foundation and JSPS KAKENHI Grant Numbers JP19K04465. 
1 Supporting Information is available on

2 http://dx.doi.org/10.1246/cl.******.

\section{References}

$41 \quad$ C.W. Tang, S.A. VanSlyke, Appl. Phys. Lett. 1987, $51,913$.

52 C. W. Tang, S. A. VanSlyke, C. H. Chen, J. Appl. Phys. 1989, 65, 3610.

3 T. Yokota, P. Zalar, M. Kaltenbrunner, H. Jinno, N. Matsuhisa, H. Kitanosako, Y. Tachibana, W. Yukita, M. Koizumi, T. Someya, Sci. Adv., 2016, 2, 1501856.

4 M.S. White, M. Kaltenbrunner, E.D. Głowacki, K. Gutnichenko, G. Kettlgruber, I. Graz, S. Aazou, C. Ulbricht, D.A.M. Egbe, M.C. Miron, Z. Major, M.C. Scharber, T. Sekitani, T. Someya, S. Bauer, N.S. Sariciftci, Nat. Photonics, 2013, 7, 811.

5 W.A.D.M. Jayathilaka, A. Chinnappan, J.N. Tey, J. Wei, S. Ramakrishna, J. Mater. Chem. C, 2019, 7, 5553.

6 T. R. Hebner, C. C. Wu, D. Marcy, M. H. Lu, J. C. Sturm, Appl. Phys. Lett. 1988, 72, 519.

7 J. Bharathan, Y. Yang, Appl. Phys. Lett. 1998, 72, 2660.

8 R. Satoh, S. Naka, M. Shibata, H. Okada, H. Onnagawa, T. Miyabayashi, T. Inoue, Jpn. J. Appl. Phys. 2004, 43, 7725.

9 R. Satoh, S. Naka, M. Shibata, H. Okada, H. Onnagawa, T. Miyabayashi, T. Inoue, Jpn. J. Appl. Phys. 2006, 45, 1829.

10 K.Matsui, J. Yanagi, M. Shibata, S. Naka, H. Okada, T. Miyabayashi, T. Inoue, Mol. Cryst. Liq. Cryst. 2007, 471, 261.

11 M. Ohmori, S. Ueno, N. Kurachi, M. Sawamura, M. Hattori, T. Inoue, T. Miyabayashi, Y. Takao, S. Hibino, I. Tsuchiya, H. Bessho, K. Ohara, M. Ohama, M. Hoshino, S. Ayukawa, R. Miyasato, N. Tsutsui, N. Miura, M. Yamanaka, S. Naka, M. Shibata, H. Okada, Jpn. J. Appl. Phys. 2008, 47, 472

12 R. Satoh, S. Naka, M. Shibata, H. Okada, T. Inoue, T. Miyabayashi, Jpn. J. Appl. Phys. 2011, 50, 01BC09.

13 S. Shimizu, A. Uchida, S. Oshima, I. Onishi, S. Fujisawa, Crystallographic Society of Japan, 1995, 37, 33.

14 S. Shirai and J. Kido, J. Photopolym. Sci. Technol. 2001, 14, 317.

15 A. Pogantsch, G. Trattnig, G. Langer, W. Kern, U. Scherf, H. Tillmann, H.-H. Hörhold, E. Zojer, Adv. Mater. 2002, 14, 1722.

16 A. Pogantsch, S. Rentenberger, G. Langer, J. Keplinger, W. Kern, E. Zojer, Adv. Funct. Mater. 2005, 15, 403.

17 M. Vasilopoulou, D. Georgiadou, G. Pistolis, P. Argitis, Adv. Funct. Mater. 2007, 17, 3477.

18 D. G. Georgiadou, M. Vasilopoulou, G. Pistolis, L. Palilis, D. Dimotikali, P. Argitis, phys. stat. sol. (a) 2008, 11, 2526.

19 T. Takahashi, Y. harada, N. Sato, K. Seki, H. Inokuchi, S. Fujisawa, Bull. Chem. Soc. Jap. 1979, 52, 380.

20 V. Nardello, M.-J. Marti, C. Pierlot, J.-M. Aubry, J. Chem. Ed. 1999, 76, 1285.

21 V. Podzorov, V. M. Pudalov, M. E. Gershenson, Appl. Phys. Lett. 2004, $85,603$.

22 E. Fumagalli, L. Ralmondo, L. Silvestri, M.Moret, A. Sassella, M. Campione, Chem. Mater. 2011, 23, 3246.

23 S. Uttiya, L. Raimondo, M. Campione, L. Miozzo, A. Yassar, M. Moret, E. Fumagalli, A. Borghesi, A. Sassella, Synth. Met. 2012, $161,2603$.

24 T. Tsuji, S. Naka, H. Okada, H. Onnagawa, Curr. Appl. Phys. 2005 5,1 .

25 M. Matsumura, T. Furukawa, Jpn. J. Appl. Phys. 2001, 40, 3211.

26 M. Matsumura, T. Furukawa, Jpn. J. Appl. Phys. 2002, 41, 2742.

27 K. Segi, S. Naka, H. Okada, J. Photopolym. Sci. Tec. 2014, 27343.

28 Y. Kijima, N. Asai, S. Tamura, Jpn. J. Appl. Phys. 1999, 38, 5274.

29 Y. Kanai, T. Matsushima, H. Murata, Thin Solid Films 2009, 518, 537.

30 S. Scholz, D. Kondakov, B. Lüssem, K. Leo, Chem. Rev. 2015, 115, 8449 . 
NOTE The diagram is acceptable in a colored form. Publication of the colored G.A. is free of charge.

For publication, electronic data of the colored G.A. should be submitted. Preferred data format is EPS, PS, CDX, PPT, and TIFF.

If the data of your G.A. is "bit-mapped image" data (not "vector data"), note that its print-resolution should be 300 dpi.

You are requested to put a brief abstract (50-60words, one paragraph style) with the graphical abstract you provided, so that readers can easily understand what the graphic shows.

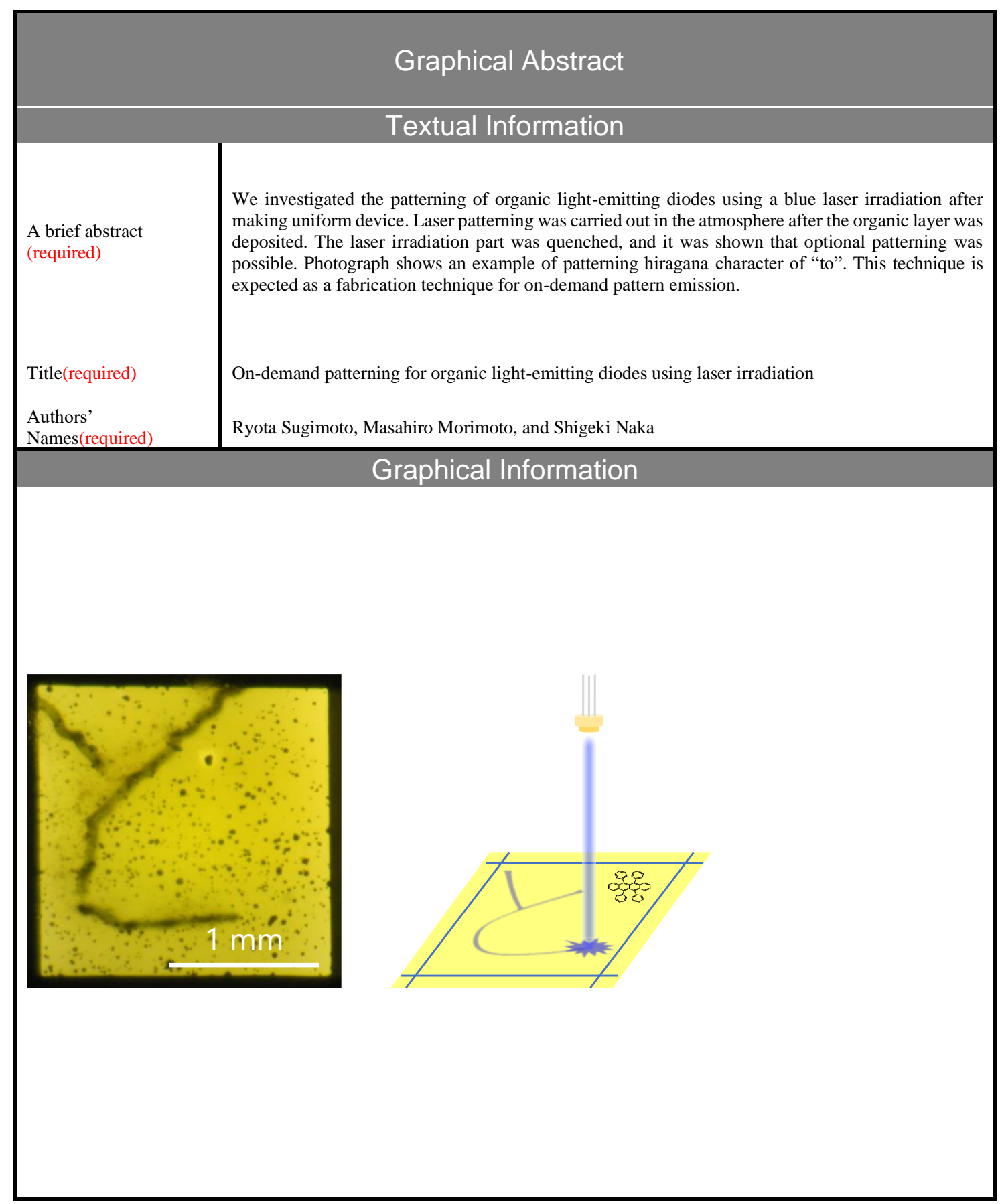

